\title{
Los procesos de secularización y pos-secularización a la luz de la sociología weberiana de la racionalización
}

Eduardo Weisz'

\section{Resumen}

En el artículo se parte de plantear una serie de problemas con los que en los últimos años se ha cuestionado la perspectiva clásica sobre el fin de las religiones en la Modernidad. Esto permite establecer un marco desde el cual analizar la teoría de la secularización de Max Weber. Este autor se abocó desde 1904 a analizar el proceso histórico-universal de racionalización, y en su análisis del mismo reside su perspectiva sobre la secularización. Se analiza en esta clave su sociología de la religión, para entender en ésta su mirada por la cual las religiones dejan de tener un lugar central en la constitución de las conductas de vida de los individuos modernos. A partir de este análisis, se presentan un conjunto de interrogantes ligados al proceso de des-secularización en los que el legado weberiano puede aportar a su desentrañamiento.

Palabras Clave: Max Weber. Racionalización. Secularización. Desencantamiento del mundo.

\section{Introducción}

El propósito del siguiente trabajo es, en un primer apartado, tomar algunas líneas directrices de la discusión abierta en las últimas décadas sobre el proceso de des- o pos-secularización. Esto permitirá definir ejes centrales en las polémicas contemporáneas, los que enmarcarán el abordaje que se hará de la teoría weberiana de la racionalización. Para ello se analizará, en el segundo apartado, la conceptualización del pensador alemán a los fines de exponer lo que puede ser llamada su teoría de la secularización. Si bien el propio autor utiliza escasas veces este término, los estudios sobre la Modernidad en general,

Doctor en Ciencias Sociales (UBA y EHESS) Docente e Investigador en la Facultad de Ciencias Sociales - Universidad de Buenos Aires.E-mail: eduardoweisz@hotmail.com. 
y los que tratan específicamente con el proceso por medio del cual la religión es desplazada del lugar social decisivo que ocupó en las sociedades tradicionales, encuentran en la obra weberiana una referencia ineludible. Se desarrollará en profundidad su perspectiva, a la luz de una interpretación de los ejes centrales de su análisis y del sentido en el que, en sus palabras, las raíces religiosas de la Modernidad ya se habrían secado. A partir de esto, en un tercer apartado, se plantearán una serie de interrogantes sobre el problema religioso en las sociedades contemporáneas, proceso en los cuales los caminos abiertos por el autor alemán abren interesantes líneas de análisis.

Para comprender la perspectiva weberiana sobre la relación entre religión y sociedad, los estudios agrupados en los Gesammelte Aufä̈tze zur Religionssoziologie (GARS) constituyen indudablemente la fuente principal. A mi entender, su sociología de la religión fue su preocupación más sistemática y constante desde 1904, y la principal desde 1910. Esto no quita relevancia, naturalmente, al resto de su producción en ese período, el que también incluye algunos problemas que lo ocuparon prolongadamente. Pero si su interés por las características de la Modernidad occidental toma una clara dirección desde 1904 - año de publicación en el Archiv für Sozialwissenschaft und Sozialpolitik de la primera parte del ensayo sobre el protestantismo (WEBER, 1904) ${ }^{2}$-, es sin duda en esta fracción de su producción en la que debe buscarse los simientes de su perspectiva sobre la cultura moderna.

Por otro lado, Weber señalaba en 1920 que, más allá de su interés inicial por la Modernidad occidental, su investigación se había encaminado a las "relaciones histórico-universales entre religión y sociedad" (1988b, p. 206; énfasis original) ${ }^{3}$.

Dicho esto, conviene también recuperar una afirmación de Weber en la cual señala que su indagación, más que como una sociología de la religión,

2 En el número siguiente de la misma revista, en 1905. Weber publicó la segunda parte del ensayo (WEBER, 1905). En 1920, luego de efectuarles importantes cambios, ambas partes se publicarian juntas como parte del Tomo I de GARS (WEBER, 1986b).

3 La declaración pertenece a "La ética protestante...", pero es un agregado para la versión de 1920, en el que el autor afirma haber trabajado, desde la publicación de la primera versión en 1905, en sacar al estudio sobre el protestantismo de su aislamiento para inscribirlo en el desarrollo cultural en su totalidad. La explicitación de este nuevo horizonte emplaza más aún a su sociología de la religión en la fracción de su obra a la que hay que dirigirse primordialmente para analizar su concepción de la secularización. 
debiera ser entendida como una sociología del racionalismo. Razón y religión son en efecto dos términos indisociablemente articulados en este autor. A su aclaración, me permito agregar que, en rigor, lo que él desarrolla es una sociología histórica del racionalismo, dado que su propósito es analizar el proceso histórico de racionalización, y esto en un doble sentido. Por un lado, es un intento de comprender genéticamente aspectos centrales de la cultura occidental moderna - de la forma de conducirse en la vida (Lebensführung) del individuo moderno - a partir del estudio de uno de sus orígenes históricos, el protestantismo, y procurando su comprensión apoyándose en la comparación con otros procesos religiosos. Por otro lado, su propósito es también establecer un modelo histórico-universal, típico-ideal, de cómo surgen las religiones universales, del proceso por el cual entran en tensión con las esferas que constituyen la vida del individuo en sociedad, y de los distintos modos en los que logran superar esa tensión.

Es de hecho así como comienza su introducción a GARS, con el planteo de su problema de investigación:

Los problemas histórico-universales son tratados inevitable y justificadamente por el hijo de la moderna civilización occidental bajo el siguiente planteamiento: ¿qué encadenamiento de circunstancias ha conducido a que aparecieran en Occidente, y sólo aquí, fenómenos culturales que - al menos como nos gusta pensarlo - se insertan en efecto en una dirección de desarrollo (Entwicklungsrichtung) de alcance y validez universales? (WEBER, 1988a, I; énfasis original).

Su sociología histórica del racionalismo es entonces un intento de entender esos fenómenos culturales específicos de la civilización occidental moderna, en el marco de un desarrollo universal que toma diferentes formas en cada civilización. En este trabajo se intentará mostrar que la concepción weberiana de la secularización es un fenómeno de Occidente pero que, sin embargo, se inscribe en un proceso universal. Su abordaje no es, por lo tanto, ajeno a las discusiones contemporáneas sobre en qué medida y en qué sentidos las reflexiones sobre el proceso de secularización han estado sesgadas por una perspectiva eurocéntrica. A la luz de esas discusiones cobra importancia, para lo que desarrollaré aquí, la mirada de Weber sobre la relación entre el proceso que tuvo lugar en el centro de Europa y el que se desarrolló en otros lugares del mundo. Este aspecto está inmediatamente relacionado con un 
desafío que a mi entender enfrentan las ciencias sociales contemporáneas, y que tiene particular importancia en lo que atañe a los procesos religiosos en la actualidad: la comprensión de los cambios en las dimensiones espaciales y temporales que conlleva el proceso de globalización, o, más precisamente, de la fase de éste que se inició en las últimas décadas del siglo anterior. Es por eso que también sobre este problema, y apoyándose en Weber, se harán algunas sugerencias en el último apartado de este trabajo.

\section{El problema}

El espíritu de la Modernidad estuvo durante siglos asociado a la idea de la creciente disolución del papel de la religión en la explicación de los fenómenos naturales y sociales. En la crítica social que surge al calor de las grandes revoluciones de los siglos XVIII y XIX, se asumía que, cuanto más moderna sea una sociedad, menos presencia religiosa habría en ella y de que el alcance de la plenitud en la modernización traería consigo, consecuentemente, la desaparición de la religión.

En el campo específico de la sociología, ya en Saint-Simon o en Comte - herederos inmediatos del espíritu de las revoluciones -, es explícita la necesidad de que la ciencia sustituya a la religión, incapacitada ya para mantener su función de cohesión social. El llamado a descubrir las leyes naturales que expliquen los fenómenos, también los sociales, sin necesidad de acudir a causas divinas seguía el modelo newtoniano, es decir, la búsqueda de las leyes universales que gobiernan los fenómenos. El punto de partida era que la religión era ya incapaz de unificar a la sociedad, y que la ciencia venía en su reemplazo.

Desde sus primeras conceptualizaciones, entonces, la Modernidad es entendida como un proceso de secularización: la asunción de que la Modernidad debe conducir, irreversiblemente, a un debilitamiento de las religiones es explícita. Como afirmó Daniel Bell, en 1977, desde el final del siglo XIX hasta la mitad del siglo XX, casi todo pensador sociológico esperaba que la religión desapareciera con los inicios del siglo XXI (1977, p. 422 y ss.). Esto es precisamente lo que en las últimas décadas fue puesto en discusión.

José Casanova señalaba hace unos años que cuatro eventos acaecidos casi simultáneamente en 1979 cambiaron el escenario y obligaron a tomar 
la religión "un poco más seriamente” (2011, p. 28). Éstos fueron: 1) La revolución islámica en Irán en 1979; 2) la elección de un Papa polaco y el ascenso del movimiento Solidaridad en Polonia; 3) la revolución nicaragüense - en parte relacionada con la teología de la liberación, cabe agregar -; y 4) la aparición del movimiento conservador Moral Majority en los Estados Unidos, con fuertes alusiones a la religión - cuyo legado hoy podemos ver en el Tea Party -. Estos eventos, para Casanova, hicieron cuestionar una de las premisas centrales de la mayor parte de las teorías de la secularización, la de que la religión se estaba convirtiendo en un fenómeno crecientemente privado e irrelevante en el mundo moderno. Si a esto sumamos fenómenos como la emergencia global del Pentecostalismo - de tanta fuerza en América Latina -, y por supuesto la enorme importancia que ha adquirido el islam en la situación política mundial desde 1979, podemos entender que Casanova haya hablado de un "resurgimiento global de la religión".

Las últimas décadas del siglo XX abrieron una polémica que para muchos, Hans Joas por ejemplo, son la manifestación del fin, o al menos de la crisis, de la teoría de la secularización. Como dice este autor, mientras que EEUU era visto como una excepción a la secularización pensada según el modelo europeo - aunque Irlanda o Polonia ya eran excepciones importantes -, ahora parece ser el prototipo de desarrollos en el sudeste asiático o en Latinoamérica; más en general: en el mundo no-europeo (JOAS, 2014, p. 16 y ss.).

Una posición extrema en este sentido es la de Peter Berger, para quien el mundo actual es, directamente, masivamente religioso, salvo dos excepciones: 1) Europa Occidental - donde con el avance de la modernización han retrocedido las prácticas y creencias religiosas - y 2) sectores sociales que han recibido educación superior, de tipo occidental, y en particular aquellos formados en humanidades y ciencias sociales (2001, p. 24 y ss.).

Beriain y Sánchez de la Yncera, a su vez, señalan que el mundo postsecular actual no se caracteriza por la ausencia de religión, aunque en algunas sociedades - sobre todo europeas -, las creencias y prácticas religiosas hayan disminuido ostensiblemente, sino más bien por una multiplicación continua de nuevas opciones, religiosas, espirituales y antirreligiosas (2010, p. 29 y ss.).

Esta diversidad había sido destacada por Charles Taylor, para quien la secularización no significa el declive de la religión, sino que el paso de una 
sociedad en la que la creencia en Dios es a-problemática, sin desafíos, a una en la que es una opción entre otras. No es que la no-creencia sea la única opción, afirma, sino que se convierte en una opción. La esencia de la secularización es, para este influyente autor, la disputa entre la creencia y la no creencia $(2007$, p. 3).

Para Eduardo Bericat Alascuey el evidente y progresivo declive de las formas institucionales y tradicionales de religión estaría compensado, hasta cierto punto, por profundas mutaciones en los modos de expresar, sentir y experimentar la religiosidad. Así, una religiosidad más individualizada y privatizada, más invisible, según la conocida tesis de Luckmann, permanecería viva en el contexto de una aparente secularización (BERICAT ALASTUEY, 2008, p. 16).

Beriain y Sánchez de la Yncera agregan complejidad al análisis del proceso contemporáneo, afirmando que más que el despertar de la religión, debería hablarse de despertares, en plural. Y esto, señala, en primer lugar porque la religiosidad surge más desinstitucionalizada, individualizada; se reafirma individualmente, con prácticas más laxas en cuanto a los ritos de las iglesias establecidas, lo que frecuentemente ha sido denominado "believingwithoutbelonging". En segundo lugar, por el surgimiento de una nueva forma de intervención religiosa en lo público. Por un lado, porque las instituciones religiosas en algunos casos protegen no sólo la libertad de culto, sino también todo tipo de libertades y derechos. A los ejemplos que da el autor, la Iglesia católica en Polonia o Brasil, podemos también sumar el caso de Moral Majority, que afirmaba que no intervenir en política consistiría un pecado. Por otro lado, también es una forma de intervención cuando la religión interfiere en la esfera pública para cuestionar la autonomía absoluta de las esferas seculares. Es el caso de aquellos obispos que cuestionan la inmoralidad de la carrera armamentista o las consecuencias sociales del capitalismo. Esto, afirman Beriain y Sánchez de la Yncera, supone una repolitización de esferas que estaban confinadas a lo privado - la esfera religiosa y la moral -, a la vez que una vuelta a la injerencia de las normas religiosas en lo público - la esfera política y la económica. En tercer lugar, despertar de la religión por el auge de la reacción global fundamentalista. En este caso, y a diferencia de los dos primeros, se trata de una apuesta a la fusión entre la religión y la política, y 
supone un dualismo beligerante que distingue entre el creyente y el infiel (BERIAIN; SÁNCHEZ DE LA YNCERA, 2010, p. 31 y ss).

Antonio Pierucci es sin duda una expresión de quienes más se han opuesto a la idea de des-secularización. Para él, el proceso de secularización debe ser entendido como el pasaje de una situación de monopolio o hegemonía de una única religión, a un escenario diversificado de pluralismo religioso plenamente aceptado y definitivamente instalado. Desde esta comprensión, señala, no habría razones para cuestionar la tesis de la secularización (PIERUCCI, 1998, p. 122).

Para terminar este apartado, y dado que se desprende de lo presentado que existe una relativa indefinición en el campo de la sociología de la religión sobre qué debe entenderse por secularización - aunque evidentemente la Modernidad es también un término de contornos poco definidos-, conviene partir de una definición a partir de la cual se podrá analizar la perspectiva weberiana. José Casanova brinda una, que, a los fines de este artículo, permite dar forma al concepto para así contar con un parámetro desde el que leer a Weber. Para Casanova, el concepto de secularización sintetiza fundamentalmente tres sentidos: a) la decreciente importancia de la religión en general, b) el retiro de la religión de la esfera pública, y c) la liberación de las sub-esferas sociales (económica, política, científica, arte) del control de la religión. Es desde aquí, entonces, que intentaré desarrollar las líneas de pensamiento de la sociología weberiana de la racionalización.

\section{El proceso de secularización en Max Weber}

Pese a la frecuencia con la que los estudiosos de la secularización o de la pos-secularización recurren a las concepciones weberianas, conviene aclarar que el término secularización es apenas utilizado por Weber, y cuando lo hace, es en general en el sentido con el que se usó originalmente, es decir, el paso de la propiedad religiosa al ámbito civil. Más aún, ni una vez lo utiliza en el significado que hoy le damos al término, y que consiste en el interés principal de este artículo. Evidentemente, más allá del término, este autor sí se ha centrado en el proceso que hoy denominamos secularización, y, sobre todo, ha desarrollado claves de enorme relevancia para su comprensión. 
De hecho, los tres sentidos dados por Casanova al concepto de secularización constituyen elementos fundamentales de la perspectiva weberiana sobre la Modernidad. El desplazamiento sufrido por la religión en la Modernidad aparece recurrentemente en sus escritos, al punto tal que, en su mirada, nosotros, los individuos de nuestro tiempo, ya no estamos siquiera en condiciones de imaginarnos una época en el que el más allá lo era todo (einer Zeit, in welcher das Jenseits alles war) (WEBER, 1988b, p. $163 \mathrm{y}$ ss.). La época del dominio de la religión es, por lo tanto, tan lejana para un individuo moderno, que éste ni siquiera es capaz de representársela. Éste es el resultado del proceso de racionalización, de carácter histórico-universal, y en lo que sigue presentaré una lectura de los ejes principales de la construcción weberiana, los que permiten dilucidar su conceptualización sobre el proceso de secularización.

\section{I Die Entzauberung der Welt}

Max Weber analiza las raíces religiosas de la conducta de vida moderna, y es indudable que esto constituye uno de sus aportes fundamentales. Sus ensayos sobre la ética protestante y el espíritu del capitalismo, en 1904 y 1905, son el resultado de esos análisis. Pero no es menos cierto que en su última década su preocupación se amplió geográfica e históricamente. Sus estudios sobre la música, en 1910, lo conducen a la conclusión de que aún una esfera sensible, irracional en principio, estuvo también sujeta al proceso de racionalización en Occidente. Es a partir de arribar a esta conclusión que Weber se aboca a estudiar el proceso de racionalización en tanto que histórico-universal. Como se planteó al comienzo de este artículo, al editar en 1920 los ensayos sobre la ética protestante para su publicación en GARS, Weber agrega una nota al pie muy significativa. En el texto de 1905, Weber había presentado un plan de trabajo para continuar profundizando en los orígenes de la Modernidad occidental. En la nota al pie agregada para la versión de GARS, señala haber cambiado su plan original, para abocarse, en su lugar, a las relaciones histórico-universales entre sociedad y religión (WEBER, 1988b, p. 206).

A partir de 1910, entonces, Weber comenzó a investigar las grandes civilizaciones desde la perspectiva de sus éticas económicas religiosamente condicionadas, con el propósito de estudiar los diferentes tipos de 
racionalizaciones que cada una de ellas impulsó en la conducta de vida de sus seguidores. Entre 1915 y 1919, bajo el título de "La ética económica de las religiones universales", publica sus ensayos sobre el confucianismo y el taoísmo, el hinduismo y el budismo, y, por último, su estudio sobre el judaísmo antiguo. También, dentro de la misma serie, dos ensayos más conceptuales: la "Einleitung", introduciendo el proyecto, y la "Zwischenbetrachtung", el excurso que interpone entre el estudio del confucianismo y el del hinduismo.

En 1917, en "La ciencia como vocación y profesión", Weber afirmaba que "[...] el proceso científico constituye la parte más importante del proceso de intelectualización al que estamos sometidos desde hace milenios" (1985c, p. 593). En el mismo sentido, en 1920 añadía a los ensayos de 1904-05 sobre el protestantismo que con el calvinismo llegaba a su finalización (Abschluss) "[...] ese gran proceso histórico-religioso de desmagificación del mundo (Entzauberung der Welt) que comenzara con las antiguas profecías judías y que combinándose con el pensamiento científico heleno rechazó como superstición y sacrilegio la búsqueda de salvación por medios mágicos" (WEBER, 1988b, p. 94 y ss.). En ambos casos, se trata de afirmaciones que no podrían haber sido hechas con un horizonte acotado a la Modernidad occidental. El proceso de racionalización, la desmagificación del mundo, había alcanzado en su mirada una perspectiva histórico-universal.

Es en este contexto que surge en su obra un término indisociable de Max Weber, y específicamente de su perspectiva sobre la secularización. En 1913, en pleno proceso de investigación sobre las religiones universales, podemos encontrar en "Sobre algunas categorías de la sociología comprensiva" por primera vez el uso del término Entzauberung, para referirse a un desarrollo por el cual cada vez más las religiones caen en una irracionalidad teleológica (WEBER, 1985b, p. 433).

La expresión, Entzauberung, es un derivado de Zauber, magia, y literalmente puede traducirse como desmagificación, aunque frecuentemente se lo traduce como desencantamiento. Friedrich Tenbruck mostró que Weber utiliza el término en dos sentidos distintos, que él propuso convincentemente

4 El término Entzauberung puede hallarse cuatro veces en "La ética protestante..." pero en todos los casos son agregados hechos para la versión de GARS de 1920. 
desdoblar en Entzauberung y Modernisierung (1999, 65 y ss.). En lo que sigue, me detendré en analizar cada uno de estos procesos por separado.

\section{I.I El proceso de Entzauberung-desmagificación}

El primero de estos procesos es el que comienza en lo que Jaspers denominó la era axial, es decir, la etapa que, en el primer milenio antes de Cristo, da lugar al surgimiento de las religiones de salvación. Este quiebre para Weber supone, típico-idealmente, la ruptura con la magia - Entzauberung literalmente -. El proceso es vehiculizado por las profecías, las que suponen un conjunto de mandamientos y de normas éticas. Las profecías racionalizan relativamente la vida, al romper con el papel que jugaban magos o mistagogos - éstos, ligados a misterios, término de igual raíz etimológica- en religiones que en forma arbitraria y asistemática premiaban o castigaban las conductas de sus seguidores. Las profecías supusieron un conjunto de normativas éticas y es en este específico sentido que Weber ve en ellas un avance en la racionalización de la conducta. Se trató, para este autor, de una "era profética", con consecuencias inmediatas en la sistematización de la vida práctica, en la conformación de un modo de conducirse en la vida (Lebensführung). Weber sostiene en Historia económica general que "[p]ara quebrantar la fuerza de la magia e imponer racionalización a la conducta de vida sólo ha habido, en todos los tiempos, un medio: el de las grandes profecías racionales" (1958, p. 308). Son los profetas, prosigue, quienes suscitaron la Entzauberung der Welt, sentando los fundamentos para la ciencia, la técnica y el capitalismo modernos (WEBER, 1958, p. 309).

En su ensayo sobre el confucianismo Weber planteaba dos criterios para evaluar el estadio de racionalización en el que está una religión (1988d, p. 512). Éstos nos sirven para entender la singularidad del judaísmo antiguo, y qué lo lleva a considerar a esta religión como un avance fundamental en el proceso de racionalización. El primer criterio, el grado en que se ha despojado de la magia. En el viejo Israel, Weber destaca el rol de los levitas en la racionalización del culto, sobre todo en contraste con el culto egipcio a los muertos o con las prácticas orgiásticas en el culto a Baal entre los cananeos. El segundo criterio es el grado de sistematización de la relación entre dios y el mundo. En este aspecto, Weber muestra como en el judaísmo antiguo los rituales como forma de cumplimentar con la religión fueron reemplazados 
por una ética, por mandamientos que cada individuo debía cumplir en su relación con el mundo.

También al comienzo del Tomo III de GARS - en el que se ocupa del judaísmo antiguo -, Weber da pautas sobre cómo comparar a esta religión con las de su entorno, encontrando una consecuencia y sistematización racionales en esta religión que superan claramente las de las culturas que la rodean (1988f, p. 15 y ss.).

En este sentido, entonces, desde el punto de vista histórico el judaísmo antiguo tuvo una enorme importancia por ser parte de los orígenes de la civilización occidental. Weber afirma que: “[...] el judaísmo tuvo una importancia decisiva para el capitalismo racional moderno, en cuanto legó al cristianismo su hostilidad hacia la magia". Con esto, agrega, "prestó un gran servicio histórico-económico", pues el capitalismo no pudo haber surgido en una cultura atenazada por la magia, uno de los más grandes obstáculos a la racionalización de la vida económica (WEBER, 1958, p. 307 y ss.).

\section{I.2 El proceso de Entzauberung-modernización}

Prosiguiendo con la distinción propuesta por Tenbruck, quiero ahora detenerme en el segundo sentido del término Entzauberung, éste directa y específicamente asociado a la Modernidad occidental. Para Weber se trata de una consecuencia no deseada de la Reforma protestante, y, sin embargo, es un proceso que está inmediatamente relacionado, paradojalmente, con la secularización, en el sentido que acá me interesa. Aquí, Entzauberung no tiene que ver con una ruptura con la magia. Probablemente, el hecho de que su comprensión de lo moderno esté tan condicionada por su estudio de las religiones universales sea la razón por la cual Weber utiliza frecuentemente una serie de metáforas de origen religioso. Así, hablará de guerra de dioses en la Modernidad, para referirse a la lucha entre valores seculares; la elección íntima que un individuo moderno hace de sus valores será referida con la idea de que cada uno elige cuál es su dios y cuál su diablo. De modo que con Entzauberung, en el sentido de modernización, no remite al fin de la magia, sino, más bien, al desplazamiento de todo aquello que no puede ser sujeto al cálculo, de lo irracional.

Esto puede apreciarse en este párrafo de "La ciencia como vocación y profesión": 
La intelectualización y racionalización crecientes [...] (...) significan que se sabe o se cree que en cualquier momento en que se quiera se puede llegar a saber que [...] no existen en torno a nuestra vida poderes ocultos e imprevisibles, sino que, por el contrario, todo puede ser dominado mediante el cálculo (durch Berechnen beherrschen könne). Esto significa la desmagificación del mundo (Das aber bedeutet: die Entzauberung der Welt). A diferencia del salvaje, para quien tales poderes existen, nosotros no tenemos que recurrir ya a medios mágicos para controlar los espíritus o moverlos a piedad. Esto es cosa que se logra merced a los medios técnicos y al cálculo. Éste es, sobre todo, el significado de la intelectualización. [...] este proceso de desmagificación (Entzauberungsprozeß), prolongado durante milenios en la cultura occidental, [...] este "progreso" en el que la ciencia se inserta como elemento integrante y fuerza propulsora [...]. (WEBER, 1985c, p. 594).

Lo que Weber dice acá, centrándose en Occidente - nosotros, dice -, es precisamente lo que desarrolla, como veremos, en la "Zwischenbetrachtung", el ensayo conceptual del primer tomo de GARS que ya mencioné, aunque en ese ensayo la perspectiva trascienda parcialmente los límites de Occdiente. En el pasaje recién citado, se hace referencia al proceso completo de Entzauberung: por un lado toma al salvaje y a la magia, por otro enfatiza la posibilidad actual, nuestra, de dominar todas las cosas a través de medios técnicos y del cálculo.

Lo que me interesa destacar aquí, es que Weber no deja mucho lugar para la religión en la Modernidad, ni siquiera para las que considera más racionales, como el protestantismo. En cambio, la forma moderna de racionalización de la conducta de vida tuvo para él la consecuencia de que la religión ha sido relegada a lo que, desde una perspectiva contemporánea, debe ser visto como irracional.

En mi opinión, entonces, lo que Weber denomina Entzauberung en el proceso moderno - y en un sentido metafórico -, es su perspectiva específica sobre la secularización.

En “La ética protestante...", Weber (1988b, p. 194 y ss.) insiste reiteradamente en esto: el capitalismo contemporáneo es completamente independiente de la religión, es una carcaza (Gehäuse) vaciada ya de religión, el espíritu del capitalismo es contrario o indiferente a la religión, John Bunyan - célebre escritor puritano inglés -, fue reemplazado por Robinson Crusoe. Incluso, como mencioné, señala que en tanto que sujetos modernos, ni podíamos imaginarnos ya lo que significaba estar sujeto a la presión de la preocupación religiosa por lo que ocurrirá con cada uno en el más allá. 
El espíritu que Weber tipifica con Franklin, está desprovisto ya de sus fundamentos religiosos: éstos, en comparación con el tipo ideal que el autor construye en torno a Baxter, ya se habían extinguido.

$\mathrm{Su}$ desarrollo de la secularización puede encontrarse, sobre todo, en el "Excurso" ("Zwischenbetrachtung"). El título de este ensayo - cuya primera versión fue publicada en 1915, y luego editada por Weber para el Tomo I de GARS - es "Teoría de los estadios y direcciones del rechazo religioso del mundo". Sin embargo, como afirmó Robert Bellah, el título es inadecuado e impreciso, y se entiende mejor el sentido y la relevancia del ensayo si se lo piensa, más bien, como el rechazo del mundo a las religiones (2005, p. 129 y ss.). Es la lógica interna de cada una de las diferentes esferas de la vida la que expulsa progresivamente la cosmovisión religiosa que unía, en forma ingenua, agrega Weber, cada esfera con la religión, y por lo tanto a las esferas entre sí, antes dela Modernidad (1988e, 540 y ss.). Se trata, en otros términos, de lo que Casanova denomina la liberación de las sub-esferas sociales del control de la religión.

Para Weber la ciencia, que suele verse como la fuerza motriz del proceso de secularización, no es en absoluto la única fuerza que arrojó la religión al campo de lo irracional. La "Zwischenbetrachtung" es muy clara al respecto, y brinda explicaciones del proceso histórico que tiene lugar típico-idealmente al interior de cada una de las esferas que presenta en este ensayo. La ciencia tiene un papel central en la esfera del conocimiento, naturalmente, pero en la economía, la política, el arte y la erótica es la propia dinámica crecientemente racional en cada esfera, el despliegue de su lógica inmanente, de su legalidad interna (Eigengesetzlichkeit), la que choca con la ética religiosa y termina consecuentemente expulsando a - y liberándose de - la religión.

Por otro lado, Weber hace referencia reiteradas veces, por ejemplo en la "Introducción" a "La ética económica de las religiones universales", a una encuesta que muestra que en 1906 sólo una pequeńa minoría, entre el proletariado, contestaba a la pregunta por su falta de fe religiosa aludiendo a los avances en el conocimiento científico (1988c, p. 242). La mayor parte de los encuestados contestaba refiriendo a la injusticia en el mundo, un problema al que Weber denominó la teodicea del sufrimiento. Para él, a medida que la racionalidad fue incrementándose, la necesidad de explicar la disparidad entre mérito y destino, es decir, por qué la gente que obra bien frecuentemente 
sufre mientras la que lo hace mal a menudo prospera, se hizo más importante porque la religión necesitó dar una explicación, mostrar que el mundo tenía un sentido ético racional. En esto, Weber veía un problema de alcance universal, al que por lo tanto todas las religiones tuvieron que dar alguna repuesta.

La respuesta protestante, la del Deus Absconditus, que había servido como respuesta al problema de la teodicea a comienzos de la Modernidad, a principios del siglo XX ya no podía evitar el declive en la fe religiosa.

Paradojalmente, fue para Weber la propia Reforma protestante la que propició un proceso de secularización interna, al reforzar entre los fieles el interés por el mundo. Se trata de un caso de consecuencias no deseadas de la acción religiosa, ya que fue la propia religión la que se secularizó. Como lo expresó Marcel Gauchet, y creo que Weber lo podría haber expresado en iguales términos, el cristianismo es la religión que produjo la "salida de la religión".

Por lo dicho hasta aquí, Weber debe ser considerado, en principio, parte de para quienes la secularización es consustancial al surgimiento de la Modernidad, como fin de un proceso de intelectualización al que los seres humanos estuvieron sujetos durante milenios.

Volveré luego a la perspectiva weberiana sobre la secularización moderna, para ver qué significa para él la salida de la religión.

\subsection{El proceso de Entzauberung como proceso histórico- universal}

En el punto anterior, destaqué la importancia que Weber asigna al judaísmo como parte de una historia de desarrollo que tiene su desenlace en el Occidente moderno. Pero el judaísmo tiene también una característica que despertó su interés: es la religión que, debido a condicionantes externos, permitió un cuadro más puro del proceso de racionalización. Ésta es la razón por la cual el judaísmo antiguo es también, para el pensador alemán, un medio de orientación heurístico; es decir, un parámetro para comparar otros procesos religiosos, dado el carácter más consistente que allí tuvo la racionalización, o, más específicamente, la desmagificación.

Weber señala que bajo la influencia de circunstancias históricas, las religiones se diferencian a partir "[...] de primitivas representaciones divinas de 
espíritus animistas y dioses heroicos que, en todos lados, eran muy parecidos" (1988c, p. 258).

Para Weber, como ya señalé, sólo las profecías racionales pudieron quebrar la magia e imponer racionalización a la vida. Sin embargo, agrega, no toda profecía destruye el poder de la magia. Lo que me interesa destacar acá, es que este autor ve en todas las profecías la capacidad potencial de desmagificar el mundo. Son razones políticas las que aduce para explicar que en el confucianismo no se haya permitido el surgimiento de una profecía y, consecuentemente, el de una religión de salvación. En la India, en cambio, razones estamentales - de casta - influyeron en que el carácter profético quedara limitado a una capa monacal, careciendo por lo tanto de la proyección social, y por lo tanto histórica, que tuvo la profecía judía. El camino de la gnosis, propio del hinduismo, sólo podía ser accesible para esa aristocracia.

En su estudio sobre el judaísmo antiguo, sostiene que "[...] en un aspecto importante la ética israelita era singular en comparación con la egipcia y también con la mesopotámica: en su relativamente avanzada sistematización racional” (1988f, p. 271). Ésta es la razón por la cual ve en el judaísmo antiguo un fenómeno histórico, real, que por su máximo de unidad racional se convierte en un tipo ideal adecuado para pensar el proceso históricouniversal y para contrastar con el surgimiento de otras religiones de salvación. Esto fue analizado por Wolfgang Schluchter, quien afirma que "[1] a dirección de desarrollo general para la ética religiosa Weber la logra sintetizar a través de la religión del viejo Israel. En esto yace su significado extraordinario [...]" (1981, p. 56).

El interés de Weber en su última década, "la relación histórico-universal entre sociedad y religión", nos permite contextualizar el estudio sobre el judaísmo y su abordaje. Es elocuente su argumento en contra de la teoría de Nietzsche sobre el surgimiento de las religiones. Weber se opone a la idea de éste de que habrían surgido como producto del resentimiento de los sectores oprimidos, pero no porque esto no haya ocurrido, sino porque no es algo que se haya dado en todos lados (keineswegs universell zutreffend) (1988c, p. 248). El propósito que perseguía en sus ensayos conceptuales era encontrar lo histórico-universal, y, para lograr ese fin, sus estudios de civilizaciones concretas fueron insumos. 
El estadio más primitivo, caracterizado por la magia y los linajes, tiene en su conceptualización un carácter universal, como se desprende inequívocamente de los primeros apartados de la sociología religiosa de Economía y sociedad. Al referirse al proceso por el cual se conforman los dioses en todas las religiones, Weber hace explícita su perspectiva, al afirmar: "Para nuestros fines, tiene muy poco interés el recorrer los casos particulares de dioses y demonios, pese a que - o, en realidad, porque - éstos están naturalmente [...] condicionados por la situación económica y el destino histórico de cada pueblo en particular" (1980, p. 251).

Al referirse a una característica singular del judaísmo, el pacto entre Yahweh y los fieles, Weber afirma significativamente: "El carácter tan específico de la religiosidad israelita de basarse en una promesa, que en esta intensidad no se repite en ninguna otra - pese a las tantas analogías en otras cosas -, tuvo aquí sus primeras raíces" (1980, p. 253). Las diferencias entre las religiones son, por lo tanto, en intensidad. En el mismo sentido, al desarrollar la sistematización y racionalización que conlleva el surgimiento de dioses en ruptura con concepciones mágicas, concluye señalando: "Además, no toda ética religiosa ha recorrido el camino hacia estas concepciones hasta el final" (1980, p. 268). El capítulo de sociología de la religión de Economía y sociedad, así como la "Introducción” y el "Excurso" en el Tomo I de GARS, reflejan indudablemente la aspiración de Weber de encontrar aspectos históricouniversales, un camino común. Es en base al judaísmo antiguo, entonces, que él construye ese modelo procesual; un proceso que no se desarrolla exhaustivamente en todas las religiones.

\subsection{Proceso universal de racionalización y filosofía de la historia}

A partir de esta perspectiva quiero discutir con una lectura de Weber con la que tengo, parcialmente, diferencias. Dirimir este aspecto permite, en mi opinión, una mejor comprensión de la concepción weberiana de la secularización. A los fines de este artículo, dicha lectura puede sintetizarse en una frase de Antônio Pierucci, aunque en otros estudiosos de la obra weberiana puede encontrarse una interpretación similar. Seńalaba Pierucci (1998), profundo conocedor de la obra weberiana, que "[...] no cuesta recordar, 
aunque sea sólo al pasar, que Max Weber siempre fue meta-teóricamente contrario a las previsiones cerradas con pretensión nomológica de formato teleológico-hegeliano tipo filosofía de la historia. ¿Cómo entonces atribuirle la tesis del 'fin histórico de la religión'?". Sobre esto quiero detenerme ahora, pues es de una enorme importancia para entender la perspectiva del pensador alemán sobre la religión y su ocaso.

En "La ciencia como vocación y profesión”, como ya he dicho, Weber hace referencia a un "proceso de intelectualización al que estamos sometidos (unterliegen) desde hace milenios" (1985c, p. 593, énfasis propio, EW). Existe en este autor, por lo tanto, la idea de que existe una fuerza meta-histórica, un poder racionalizador, que opera sobre el individuo. A mi entender, no se trata aquí de una frase aislada, sino de una concepción que subyace al conjunto de su sociología de la racionalización.

Andreas Buss, por ejemplo, atribuye a los ensayos weberianos sobre India y China el objetivo de explicar los obstáculos que impidieron, en esas culturas, un racionalismo del tipo occidental (1987, p. 272). En realidad, subyace a esta interpretación de Buss la idea de que para Weber habría un proceso inmanente que no logra desarrollarse, que se ve obstaculizado. Tanto en China como en la India, Weber atribuye frecuentemente a impedimentos (Hemmungen) el desvío del camino que la racionalización siguió en Israel.

Cada situación histórico-concreta pareciera ser para Weber la resultante de la articulación particular entre la fuerza de una tendencia metahistórica la racionalización - y otras fuerzas históricas que en cada situación concreta la propician u obstaculizan. Siguiendo sus textos metodológicos, podemos hablar de esa fuerza a la que estamos sometidos como una posibilidad objetiva, basada en reglas dadas por la experiencia. Esto es, una causalidad adecuada, probabilística, lo cual implica que el resultado del proceso no está determinado, dada la infinitud de variables que intervienen en cada situación concreta (WEBER, 1985a, p. 177 y ss.).

Para esta lectura que propongo hay una clave muy interesante al comienzo del "Excurso". Al presentar el texto, Weber sostiene que los estadios y direcciones del rechazo religioso del mundo están construidos en ese ensayo como un tipo ideal. Sin embargo, agrega, no son solamente eso: "También lo racional, en el sentido de la 'consecuencia' lógica o teleológica de una postura 
teórico-intelectual o ético-práctica ejerce (y lo ha hecho siempre) poder sobre las personas, por más limitado y lábil que ese poder haya siempre sido y sea, frente a otros poderes en la historia" (WEBER, 1988e, p. 537). Se trata para él, entonces, de un poder metahistórico. Tiene, por lo tanto, el mismo sentido de su afirmación sobre el proceso de intelectualización al que estamos sometidos, mencionada en la conferencia sobre la vocación científica, dos años más tarde.

Por eso, en mi opinión tenemos que ubicar a Weber en esta perspectiva histórico-filosófica, por la cual el proceso histórico particular del cristianismo occidental se inscribe en un proceso teleológico universal de desarrollo del ser humano desde las religiones mágicas a la conciencia post-metafísica, racional de la modernidad, pasando por las religiones de salvación. El análisis de Weber tiene una perspectiva universal, con aspectos relativamente legaliformes, aunque sólo en el sentido en el que este autor entiende las leyes en las ciencias de la cultura: no se trata de una fuerza operante que determina mecánicamente la forma históricamente concreta en la que se desarrollan las religiones universales.

La ratio es un poder que condiciona la realidad histórica, interviene sobre ésta. El proceso de racionalización determinó, utilizando este término en un sentido laxo, el desarrollo de las diferentes civilizaciones, pero esa determinación abstracta se topó, en cada caso, con tendencias que lo favorecieron o contrarrestaron, con fuerzas que, ante determinadas condiciones históricamente determinadas, propiciaron o, en cambio, no permitieron su libre accionar.

Este problema es de una gran importancia para una interpretación de la lectura weberiana del proceso de secularización. Pensar la sociología de la religión de este autor como una particular filosofía de la historia, implica también el atribuirle un fin, un telos, a la misma. En este sentido, a diferencia de Pierucci, creo que Weber ve, a su modo, como tendencia basada en la experiencia, un fin histórico para la religión en su capacidad de determinar la vida social. Es por eso que tampoco existe la posibilidad para el individuo moderno de encontrar un sentido trascendente para la vida. La perspectiva trágica de este autor, las múltiples referencias a un pasado sin retorno, a una burocratización en todas las esferas, a la stahlhartes Gehäuse - la ironcage en la célebre, aunque imprecisa, traducción de Talcott Parsons -, suponen una idea 
de destino, no menos contundente por tratarse de una causación adecuada. Esta perspectiva, tan central en Weber, puede a mi entender comprenderse mejor, en su faceta trágicamente inevitable, si se lo enmarca en un proceso de racionalización que está inscripto en una filosofía histórica que supone un fin. Es producto de esta perspectiva metahistórica que dicho destino se le aparece como ineluctable .

Si volvemos ahora a Casanova y los tres sentidos en los que puede entenderse la secularización: a) la decreciente importancia de la religión en general, b) el retiro de la religión de la esfera pública, y c) la liberación de las subesferas sociales del control de la religión, podemos ver que las tres están explicitadas en Max Weber, como parte de su perspectiva histórica del proceso de racionalización.

\section{Problemas de la des- o post-secularización, desde una perspectiva weberiana}

En lo que sigue quiero plantear una serie de problemas en torno al proceso de las últimas décadas que fuera denominado como pos- o dessecularización. No tengo con esto ninguna pretensión de originalidad pues surgen de los planteos de quienes se han abocado a esta problemática y cuyos lineamientos intenté reflejar en el Apartado I de este artículo. Mi propósito aquí será, más bien, retomar algunas de estos problemas para considerarlos desde las concepciones weberianas sobre la secularización que presenté en el Apartado anterior.

Un primer aspecto que creo es necesario plantear desde el comienzo, es que considero que Weber tenía en mente una Modernidad mucho más homogénea de lo que el siglo transcurrido desde su muerte ha evidenciado. La idea de distintas Modernidades ha sido planteada desde diferentes ángulos, también en lo que hace a los problemas de la secularización. En este sentido, creo que el posicionamiento que subyace a su perspectiva es el que expresa al comenzar el escrito con el que introduce su sociología de la religión en el

5 Los límites de este artículo no me permiten expandirme más en mi lectura sobre la filosofía de la historia weberiana. Remito para ello a Weisz (20ll), donde he analizado este aspecto tomando en cuenta no sólo la sociología de la religión de este autor, sino también sus escritos metodológicos y, parcialmente, sus escritos políticos en los que también existen importantes indicios. 
Tomo I de GARS: los fenómenos de la Modernidad occidental están en una línea histórica de desarrollo cuyos alcances son universales. En otros términos, en este autor esos fenómenos se proyectan universalmente.

Sin embargo, lo que hoy se nos presenta como un escenario mucho menos homogéneo es el marco desde el cual quiero plantear una serie de interrogantes en los que, a mi entender, los desarrollos de Weber pueden brindarnos elementos para aportar a su comprensión. La siguiente reflexión de Casanova, apelando a un término weberiano, es un buen punto de inicio. Como señaló este autor, no sólo las así llamadas sociedades seculares de Occidente sino todo el mundo es crecientemente más secular y "desencantado": el orden cósmico está cada vez más definido por la ciencia y la tecnología modernas, el orden social cada vez más por la articulación entre estados democráticos, economías de mercado y la esfera pública mediática, y el orden moral está cada vez más definido por agentes individuales portadores de derechos, que aspiran a la dignidad, la libertad, la igualdad y la prosecución de felicidad (CASANOVA 2011, p. 32). Sin embargo, prosigue, la evidencia de renacimientos religiosos en muchos lados deja en claro que dentro del mismo marco inmanente, en el sentido de Charles Taylor, pueden encontrarse diferentes dinámicas religiosas. De ahí que el desencantamiento del mundo, concluye Casanova, no necesariamente conduce al desencantamiento de la conciencia, al decline de la religión, o al fin de la magia. Por el contrario, es compatible con todas las formas de re-encantamiento y de resurgimiento religioso.

En lo que sigue trataré de desagregar este escenario, para señalar aspectos en los que la conceptualización de este proceso por parte de Weber puede aportar a su esclarecimiento.

1. El proceso de racionalización analizado por Weber no tiene como consecuencia que las creencias religiosas dejen de existir, sino, más bien, que en la Modernidad se han convertido en una cuestión de elección personal. Al intentar explicar, como vimos, las encuestas que mostraban un declive en la religiosidad de los individuos, su preocupación apuntaba al lugar que ocupa la religión en la cultura moderna. Y la perspectiva a la que arriba es que las creencias religiosas carecen por completo de la capacidad de constituir un conjunto de valores trascendentes que dé sustento a la sociedad. Los valores, 
en cambio, se han convertido en algo íntimo, personal, propio de cada individuo, sin que ninguna autoridad legítima - tampoco la ciencia o la razón - tenga la capacidad de normativizarlos.

Esto es precisamente lo que afirmaba en su conferencia sobre la vocación científica:

El destino de nuestro tiempo está caracterizado por la racionalización y por la intelectualización y, sobre todo, por la desmagificación del mundo (Entzauberung der Welt). Precisamente los valores últimos y más sublimes se retiraron de la vida pública y se refugiaron o en el reino trascendente de la vida mística o en la fraternidad de las relaciones humanas directas y personales [...] Nada hay de accidental en el hecho de que, hoy en día, sólo en los círculos más pequeños e íntimos, en las situaciones humanas personales, en pianissimo, late algo que corresponde al pneuma profético que en los tiempos pasados atravesaba las grandes comunidades como un fuego tempestuoso y las unía, soldándolas. (WEBER, 1985c, p. 612).

Los valores que se retiraron de la vida pública, el pneuma profético cuyo fuego soldaba y así mantenía a las comunidades unidas, es decir, la religión como fuerza de cohesión social, pertenece al pasado.

Esto mismo es lo que pone de manifiesto Luhmann, cuando señala que la religión no es ya una mediación necesaria que integra todas las actividades sociales proporcionándoles un sentido unitario (2000, p. 125). El proceso por medio del cual cada esfera de la vida fue siendo crecientemente dominada por su lógica interna siguió en cada caso sus propios ritmos. En el "Excurso", cada esfera es analizada autónomamente, atendiendo a su especificidad. De ahí que, por ejemplo, incluso hoy en las sociedades que podemos considerar más secularizadas, la esfera erótica se debate todavía en su lucha contra la tutela religiosa. Sin embargo, en este proceso de independización, la religión pierde su capacidad de unificar a la vida en sociedad.

Esto no invalida, en cambio, que quienes no acepten el destino desencantado del mundo moderno puedan refugiarse en las viejas iglesias, como señala Weber (1985c, p. 612). Pero esto supone, agrega, el sacrificio del entendimiento, o como en la frase latina citada por Weber, credo quia absurdum (1988e, p. 566; ligeramente modificada): creo, porque es absurdo.

Si la religión pasa al plano íntimo, como enunciaba Weber, esto no contradiría en sí la emergencia actual de las múltiples expresiones religiosas 
que caracterizan a muchas sociedades. Pierucci, apoyándose en autores como Robbins o Wilson, ha sostenido la idea de que la multiplicación de opciones pentecostalistas, por ejemplo, se debe a la secularización de la sociedad. Y esto, porque la secularización relativiza compromisos religiosos, abriendo la posibilidad de que sean pasajeros. De ahí que, como señala Wilson, cada compra hecha por el consumidor religioso "[...] no tiene consecuencias reales para las otras instituciones, para la estructura del poder político, para los constreñimientos y controles tecnológicos" (cit. en PIERUCCI, 1998, p. 118).

Por eso, sostiene Pierucci apoyándose en Wilson, las nuevas formas de vida religiosa que surgen en los países desarrollados de Occidente, al quedar en el plano privado-individual del ejercicio religioso, o en el nivel de las relaciones personales, no tiene consecuencias de peso para las instituciones sociales dominantes, para la dinámica del poder político, para los procesos técnico-económicos, para la administración pública y la conducción de los negocios.

En este sentido, me parece que la mirada de Max Weber sobre la secularización moderna no contradice procesos como el de los Estados Unidos, donde efectivamente lo religioso mantiene una fuerte presencia, y que muchas veces es utilizado como ejemplo de los límites de la teoría de la secularización. En otros términos, en el billete de dólar puede seguir figurando la inscripción "In God we trust", pero eso no modifica en nada su carácter de instrumento de una economía absolutamente impersonalizada y racionalizada.

Esto permite explicar en parte el proceso en Occidente, en donde el florecimiento de diversas religiones puede entenderse en este marco. Sin embargo, no nos dice nada sobre el proceso en curso en aquellas sociedades en las que el islam tiene un papel decisivo en todos los órdenes sociales, con escasa diferenciación de esferas.

2. En la Modernidad desarrollada, la pujanza de lo religioso puede probablemente también atribuirse a otra causa. Como señalamos antes, la guerra de dioses moderna, utilizando la expresión de Weber, no representa un mero regreso al politeísmo griego, sino que expresa más bien una metamorfosis en la sociedad moderna y en sus estructuras de conciencia. Ya no existe un 
valor por encima de otros que proporcione una integración trascendente en la comunidad. Si la comunidad suponía un destino común, la sociedad moderna lo reemplaza, en buena parte, por la elección personal.

Pero si el individuo se rige por sus propios valores, y esto, lejos de ser algo definitivo, no es mas provisional, ¿`cómo puede encontrar un objeto que merezca su devoción apasionada? Este aspecto ha sido planteado por Richard Fenn, para quien es éste el problema religioso por excelencia (1969, p. 163). El problema de la falta de sentido del mundo moderno, de la cacofonía de respuestas posibles a la pregunta por el para qué de nuestra presencia en este mundo, es una pregunta existencial para la cual la religión tiene una respuesta, sin muchos contrincantes ${ }^{6}$.

El planteo de Fenn (1969) remite indudablemente a un problema existencial del ser humano. Desde su individualismo moral, Kierkegaard decía en su Diario: "Debo encontrar una verdad que sea verdadera para mí... la idea por la que pueda vivir o morir". Esto es lo que Weber le indica al individuo moderno desencantado, y también el sentido que él da a su propia vida ${ }^{7}$.

Los individuos siguen atados a la búsqueda de la legitimación última para sus actividades, algo que merezca su compromiso apasionado. El problema, trágico, es que ya no hay una tradición única, unificadora, ni una autoridad última que pueda garantizarle la rectitud de sus decisiones. El único oráculo que puede consultar es su propio daimon: la modernidad obliga a decidir. El término herejía proviene del griego hairein, que significa elegir. Si para el individuo pre-moderno la herejía fue una posibilidad remota, para nosotros se convierte en una necesidad, y a eso apunta Weber en las últimas palabras

6 En el "Excurso", Weber menciona tres situaciones en las que el individuo secularizado encuentra una trascendencia en su acción que rivaliza con la que provee la religión. Éstas son la del artista en la producción de su obra (1988e, p. 555), la del amante en una situación erótica (1988e, p. 56I), y la del que integra una comunidad en el campo de batalla, es decir, la del soldado que muere por su patria (1988e, p. 548). Probablemente pueda encontrarse también un sustituto a la plenitud que brinda la religión en la que proporciona cierta militancia política. Las organizaciones revolucionarias, de hecho, han tenido la capacidad de dotar de un sentido trascendente a la vida, y en ciertas condiciones politicas, a la propia muerte al servicio de una causa. En mi opinión, esta analogía resulta una clave de interpretación fundamental para aprehender ciertos aspectos subjetivos de la militancia revolucionaria.

7 Como he desarrollado en otro lugar, a mi entender la pasión que Weber sostiene a lo largo de su vida por la defensa de los valores culturales de la nación alemana puede interpretarse como un camino personal para hacer frente al proceso de racionalización (WEISZ, 2014). 
de su conferencia sobre la profesión científica: cada cual "debe encontrar el demonio que maneja los hilos de $s u$ vida y obedecerle" (1985c, p. 613, énfasis original).

Desde esta perspectiva existencial, la falta de sentido en el mundo moderno puede asociarse, entonces, al hecho de que no desaparezcan las religiones, aún cuando esto implique, como apunta Weber, el sacrificio del intelecto. Como lo han expresado Beriain y Sánchez de la Yncera, las heridas del existir alimentan la persistencia del discurso religioso (2010, p. 28).

3. Las sociedades modernas ya no pueden ser integradas a través de una religión institucionalizada. Parece indudable que, como señalaba Weber, cuanto más secularizada es una sociedad más diferenciadas están las esferas religiosa y política. Pero esto nos conduce a uno de los aspectos más relevantes del escenario político contemporáneo, el imponente florecimiento del fundamentalismo islámico. Se trata de sociedades en las que se busca subsumir todas las esferas a la religión, sirviéndose para ello del Estado. Esto supone, en la definición weberiana, el monopolio legitimo de la fuerza, es decir, la aceptación, por parte de las poblaciones, de que el Estado deba ser utilizado al servicio de lo que Beriain y Sánchez de la Yncera llaman, como ya señalé, dualismo beligerante, el que separa el creyente del infiel (2010, p. 31 y ss.).

Es indudable que este florecimiento del fundamentalismo tiene fuertes raíces políticas. La revolución en Irán contra el Sha, en 1979, fue una clara expresión de la canalización, a través de la religión, de un fuerte malestar político y social. En mi opinión, en el resurgimiento islámico posterior en el mundo árabe pueden encontrarse raíces similares. Es una forma de resistencia a una sostenida opresión, que condujo a guerras, a regímenes al servicio de una pequeña aristocracia local y, sobre todo, de las grandes potencias internacionales. Es la respuesta, en definitiva, a décadas de malestar. Como sostiene en un reciente estudio Norberto Méndez, “[...] [e]s común invocar la Jihad como una institución que busca la defensa de la fe pero no es extraño que se mate y/o se flagele en nombre del islam, argumentando en ocasiones que es la respuesta a la tortura y el aniquilamiento que realizan muchos centros de poder occidentales" (2015, p. 78). 
También en Europa, el declive de las políticas keynesianas es inescindible del resurgir del fundamentalismo: jóvenes de las banlieue en París o Marsella, franceses cuyos abuelos habían sido convocados a inmigrar desde Argelia cuando, décadas atrás, el ciclo económico necesitaba incrementar la oferta de mano de obra para evitar la tendencia alcista en los salarios, no tienen hoy muchas chances de integrarse a esa sociedad.

Probablemente este resurgimiento del islam, entonces, pueda también interpretarse en el marco de la teoría del resentimiento que propone Nietzsche, o, con Max Weber, en el de la teodicea del sufrimiento, para la cual el islam provee una explicación relativamente racional al problema del malestar de estos pueblos, una respuesta activa e intramundana que conlleva la necesidad de actuar en el mundo para transformarlo. Naturalmente, ésta es una línea de interpretación que debiera ser explorada, y que podría valerse del marco conceptual weberiano ${ }^{8}$.

En el análisis de estas sociedades en las que el fundamentalismo islámico ocupa un lugar tan preponderante, en el que la religión pareciera subsumir todas las esferas, no puede obviarse, sin embargo, la existencia de aspectos fuertemente secularizados en su seno. Los avances en tecnología nuclear en Irán, por ejemplo, o los avances tecnológicos en la extracción de petróleo en varios de estos países, no podrían haberse alcanzado sin una esfera del conocimiento escindida de lo religioso.

4) El desarrollo económico explosivo del sudeste asiático nos impone la necesidad de plantearnos la relación entre religión y modernidad, y de revisar en este sentido la perspectiva weberiana. El alcance global arrasador del capitalismo supuso, parcialmente al menos, la occidentalización del mundo. Los países asiáticos se han occidentalizado, en muchos sentidos, pero

8 Weber creía que la magia y el mito soteriológico tienden a surgir espontáneamente entre los sectores populares. De ahi que muchos procesos de racionalización en las religiones se hayan visto obstaculizados por este factor: "Con la excepción del judaismo y del protestantismo, todas las religiones y éticas religiosas, sin excepción, tuvieron que adoptar de nuevo el culto de los santos, héroes o dioses funcionales, por exigencia de las masas" (1988c, p. 297). En China, por ejemplo, una capa de funcionarios desdeñaba las religiones mágicas de los sectores populares, pero las utilizó sin embargo a los fines de mantener la dominación y el orden social. Weber no ahonda realmente en esta idea, pero creo que puede ser fértil para explicar las religiosidades populares, no sólo en los regímenes islámicos sino también, por ejemplo, en Latinoamérica. 
integrando instituciones y conductas de vida propias de sus tradiciones, algo que en los países occidentales pasó en mucho menor medida.

Weber caracterizaba al capitalismo como el poder más determinante de nuestra vida moderna (1988a, p. 4). Si la ética protestante había jugado un papel fundamental en transformar la conducta de vida tradicional, en propiciar un comportamiento racional en lo económico, el capitalismo desarrolla esa disciplina con su propia lógica: el empresario que no lleva una contabilidad racional, no paga sus deudas, o no reinvierte parte de sus ganancias, sucumbe ante la competencia; el trabajador que no cumple sus horarios, o que no evita despilfarrar su tiempo en la empresa, pierde su empleo.

Lo que resulta de interés aquí, es que Weber veía que este proceso iba necesariamente a repercutir en civilizaciones en las que la ética religiosa no lo había propiciado por sí misma. Luego de analizar por qué la religión en China no favorecía una conducta económica afín al capitalismo, Weber afirma que lo que no forjó el confucianismo, lo iba a enseñar el "empuje irrefrenablemente expansivo del capitalismo occidental" (der Eindruck des unaufhaltsam von dringenden okzidentalen Kapitalismus) (1988d, p. 529). La conducta de vida moderna, racional, que en Occidente había sido favorecida por el protestantismo en su origen, la logra el capitalismo desarrollado por sí mismo, y esto se traslada a otras civilizaciones. Naturalmente, esta perspectiva weberiana debiera ser contrastada con el proceso que está teniendo lugar en esta etapa en culturas que, con muy diferentes orígenes, están siendo parcialmente subsumidas a la lógica del capitalismo ${ }^{9}$.

5. La globalización supone necesariamente un nuevo escenario para pensar el problema de la secularización. También al respecto pueden encontrarse

9 Una investigación en la dirección aqui esbozada puede apoyarse en importantes antecedentes. Una conferencia realizada en Múnich en 1993, por ejemplo, reunió a importantes académicos japoneses y alemanes en torno a la utilidad del análisis weberiano para la comprensión del proceso de desarrollo en Japón (MOMMSEN; SCHWENTKER, 1999). El estudio de Robert Bellah (1957), a su vez, ya había dado lugar a una discusión sobre en qué medida existieron en esa sociedad equivalentes funcionales al protestantismo ascético, que habrían aportado al proceso de modernización japonés. También el libro de Renato Ortiz sobre Japón es un importante antecedente para pensar cómo se articulan alli estos dos universos, religión y modernidad; más precisamente, en qué medida un capitalismo totalmente secularizado convive con cierta religiosidad que en Japón pareciera estar relegada al plano privado (ORTIZ, 2003). 
posturas muy diversas, y la compresión de tiempo y espacio que conlleva estas transformaciones ha sido leída en sentidos incluso opuestos. Para Pierucci (1998, p. 121), por ejemplo, el nuevo escenario conduce a la convivencia más intensa de las religiones, la que tiene como consecuencia la secularización estructural de la cultura. Roland Robertson y Jo Ann Chirico (1985), en cambio, sostienen que la religión ha permitido dotar de identidad comunal a sociedades oprimidas en las que la globalización la pone en riesgo. De ahí que esta búsqueda de identidad en un mundo globalizado habría revitalizado a las religiones (ROBERTSON; CHIRICO, 1985, p. 238 y ss.).

Sin duda, la perspectiva weberiana ha sido un aporte importante en el análisis de los cambios que atraviesan las sociedades contemporáneas. En cuanto a lo que atañe a las religiones, creo que una línea de interpretación enmarcada en el legado de Weber puede partir de una característica insoslayable que tienen estas transformaciones, su carácter neoliberal. De ahí que en este período, la legalidad interna de la esfera económica redujo al mínimo el peso de la esfera política y, sobre todo, de cualquier racionalidad sustantiva que quisiera interponer valores - nacionales, sociales, éticos, por ejemplo -, a la primacía de la lógica del capital. Una investigación en este sentido, enmarcada en la perspectiva weberiana, podría comenzar preguntándose en qué medida el sujeto que surge en ese marco social, en el que su ser queda reducido a su valor en el mercado, no encuentra en la religión una salida frente a la brutalidad con la que es arrojado a la racionalidad económica. En qué medida la explosión del pentecostalismo en la década de los 90 en Argentina, o en Brasil por el mismo período, responde a este problema (también) weberiano, es algo que sólo puede encararse a través de un trabajo teórico y empírico.

Esta hipótesis puede asociarse a otro problema. Las transformaciones de estas décadas pueden también pensarse como un cambio epocal. De ahí que, siguiendo la perspectiva de Weber sobre la Modernidad, ¿puede pensarse el proceso de des-secularización o pos-secularización como un signo del fin de la Modernidad clásica? El debate sobre la pos-modernidad está abierto, pero el resurgimiento de las religiones probablemente dé cuenta de una nueva etapa en la historia. En este sentido puede pensarse un comentario de Weber al final de "La ética protestante...": no sabemos si profetas completamente nuevos o un poderoso renacimiento de ideas e ideales antiguos estará al final de este prodigioso desarrollo (1988b, p. 204). Esta idea sobre la sociedad posterior al 
desarrollo moderno no vuelve a aparecer en otro texto, pero es un indicio de una salida posible - aunque, en mi opinión, improbable para él - al vacío que, en la Modernidad, dejan las religiones en el individuo.

Sin ser especialista en los procesos religiosos contemporáneos, los puntos que señalé permiten ponderar en qué medida los desarrollos de Weber pueden aún aportar a entender el heterogéneo resurgimiento de las religiones en esta etapa. Con aspectos en los que, indudablemente, sus perspectivas se mostraron imprecisas, la inscripción del proceso de secularización en un marco históricouniversal, su análisis a través de los procesos seguidos en las grandes religiones, abren fecundas vías de reflexión para la comprensión del papel que juegan las religiones en el mundo actual.

\section{Referencias}

BELL, D. The return of the sacred? The argument on the future of religion. British Journal of Sociology, v. 28, n. 4, p. 419-449, 1977.

BELLAH, R. Tokugawa Religion: The Values of Pre-Industrial Japan. Illinois: The Free Press, 1957.

Max Weber y el amor negador del mundo: Una mirada a la sociología histórica de la religión. In: ARONSON, P.; WEISZ, E. (Comp.). Sociedad y religión. Un siglo de controversias en torno a la noción weberiana de racionalización. Buenos Aires: Prometeo, 2005. p. $127-156$.

BERGER, P. La désécularisation du monde: un point de vue global. In: (Dir.). Le réenchantement du monde. París: Fayard, 2001. p. 13-36.

BERIAIN, J.; SÁNCHEZ DE LA YNCERA, I. Introducción: las derivas polimorfas de la post-secularidad. In: (Ed.). Sagrado/Profano. Nuevos desafíos al proyecto de la modernidad. Madrid: Centro de Investigaciones Sociológicas, 2010. p. 7-38.

BERICAT ALASTUEY, E. Duda y posmodernidad: el ocaso de la secularización en Europa. Revista Espańola de Investigaciones Sociológicas, n. 121, p. 13-53, 2008.

BUSS, A. Introductory Comments on Max Weber's Essays on India and China. International Sociology, v. 2, n. 3, p. 271-276, 1987.

CASANOVA, J. From Modernization to Secularization to Globalization. Religion and Society: Advances in Research, "Portraits", v. 2, p. 25-36, abr. 2011. 
FENN, R. Max Weber on the Secular. A Typology. Review of Religious Research, v. 10, n. 3, p. 159-169, 1969.

JOAS, H. Faith As An Option. Possible Futures for Christianity. Stanford: Stanford University Press, 2014.

LUHMANN, N. Die Religion der Gesellschaft. Frankfurt am Main: Suhrkamp, 2000.

MÉNDEZ, N. R. Las redes sociales y el islam político. Casos: Egipto y el Estado Islámico. Ciencias Sociales, n. 88, p. 76-81, 2015.

MOMMSEN, W. J.; SCHWENTKER, W. (Ed.). Max Weber und das moderne Japan. Gottingen: Vandenhoeck \& Ruprecht, 1999.

ORTIZ, R. Lo próximo y lo distante. Japón y la modernidad-mundo. Buenos Aires: Interzona, 2003.

PIERUCCI, A. F. Soltando amarras: secularización y destradicionalización. Sociedad y Religión, n. 16/17, p. 101-131, 1998.

ROBERTSON, R.; CHIRICO, J. Humanity, Globalization, and Worldwide Religious Resurgence: A Theoretical Exploration. Sociological Analysis, v. 46, n. 3, p. 219-242, 1985.

SCHLUCHTER, W. Altisraelitische religiöse Ethik und okzidentaler Rationalismus. In: (Ed.). Max Webers Studie über das antike Judentum. Interpretation und Kritik. Frankfurt am Main: Suhrkamp, 1981. p. 11-77.

TAYLOR, C. A Secular Age. Cambridge, Mass: Harvard University Press, 2007.

TENBRUCK, F. Das Werk Max Webers. In: Das Werk Max Webers, Tübingen: MohrSiebeck, 1989. p. 59-98.

WEBER, E. Racionalidad y tragedia. La filosofía histórica de Max Weber. Buenos Aires: Prometeo, 2011.

. Nación y racionalización: dos focos en tensión en los escritos políticos de Max Weber.

Estudios Sociológicos, v. XXXII, n. 96, p. 681-708, 2014.

WEBER, M. Die protestantische Ethik und der "Geist" des Kapitalismus. I. Das Problem. Archiv für Sozialwissenschaft und Sozialpolitik, v. 20, p. 1-54, 1904.

. Die protestantischeEthikund der "Geist" des Kapitalismus. II. Die Berufsidee des asketischen Protestantismus. Archiv für Sozialwissenschaft und Sozialpolitik, v. 21, p. 1-110, 1905. 
Wirtschaftsgeschichte. Abriß der universalen Sozial- und Wirtschaftsgeschichte. Berlín: Duncker \& Humblot, 1958.

Wirtschaft und Gesellschaft: Grundriss der verstehendenSoziologie. Tübingen: Mohr-Siebeck, 1980.

Die "Objektivität" sozialwissenschaftlicher und sozialpolitischer Erkenntnis. In: esammelte Aufsätzezur Wissenschaftslehre, Tübingen: Mohr- Siebeck, 1985a. p. 146-214. Über einige Kategorien der verstehenden Soziologie. In: Gesammelte Aufsätze zur Wissenschaftslehre, Tübingen: Mohr-Siebeck, 1985b. p. 427-474.

. Wissenschaft als Beruf. In: Gesammelte Aufsätze zur Wissenschaftslehre, Tübingen: Mohr-Siebeck, 1985c. p. 582-613.

. Vorbemerkung. In: Gesammelte Aufsätze zur Religionssoziologie, I. Tübingen: Mohr-Siebeck, 1988a. p. 1-16.

Die protestantische Ethikund der Geist des Kapitalismus. In: Gesammelte Aufsätze zur Religionssoziologie, I. Tübingen: Mohr-Siebeck, 1988b. p. 17-206.

Die Wirtschaftsethik der Weltreligionen: Einleitung. In: Gesammelte Aufsätze zur Religionssoziologie, I. Tübingen: Mohr-Siebeck, 1988c. p. 276-536.

Die Wirtschaftsethik der Weltreligionen: Konfuzianismusund Taoismus. In: Gesammelte Aufsätze zur Religionssoziologie, I. Tübingen:Mohr-Siebeck, 1988d. p. 237-275.

. Die Wirtschaftsethikder Weltreligionen: Zwischenbetrachtung. Theorie der Stufenund Richtungen religiöser Weltablehnung. In: Gesammelte Aufsätze zur Religionssoziologie, I. Tübingen: Mohr-Siebeck, 1988e. p. 536-573.

Die Wirtschaftsethik der Weltreligionen: Das antike Judentum. In: Gesammelte Aufsätze zur Religionssoziologie, III. Tübingen: Mohr-Siebeck, 1988f. p. 1-400. 


\section{Secularization and de-secularization processes under the light of Max Weber's rationalization sociology}

\section{Abstract}

This article starts posing a number of problems with which the classical understanding of the end of religions in Modernity has been confronted. This allows for a framework from which Max Weber's theory of secularization can be addressed. From 1904 onwards, this author was engaged in the understanding of the historical-universal process of rationalization, and it is in this analysis where his prospective of secularization has to be looked for. His sociology of religion is therefore deconstructed from this point of view, so as to grasp why he understood that religions were displaced in the constitution of modern life conducts. After this analysis, the article poses the importance of this author's legacy for the understanding of different issues concerning the present process of rebirth of religions.

Keywords: Max Weber. Rationalization. Secularization. Disenchantment of the world.

Recebido em: 10/11/2016

Aprovado em: 14/01/2017 